\title{
Predictors of dopamine agonist resistance in prolactinoma patients
}

\author{
Elle Vermeulen', Jean D'Haens ${ }^{1}$, Tadeusz Stadnik², David Unuane ${ }^{3}$, Kurt Barbe ${ }^{4}$, Vera Van Velthoven ${ }^{1}$ \\ and Sven Gläsker ${ }^{1 *}$
}

\begin{abstract}
Background: Surgical resection of prolactinomas resistant to dopamine agonists is frequently incomplete due to fibrotic changes of the tumour under pharmacological therapy. In order to identify a subgroup of patients who may benefit from early surgery, we thought to investigate possible predictive factors of pharmacological resistance of prolactinomas to dopamine agonists.

Methods: We retrospectively analyzed a database of a Belgian tertiary reference center for patients with pituitary tumours from 2014 to 2016. The groups of interest were patients with dopamine agonist responsive and resistant prolactinomas. The possible predictive factors, including MRI findings, endocrinological parameters, response of tumour and patient factors for dopamine agonist resistance were investigated.

Results: We included 69 patients of whom 52 were women (75,4\%) and 17 were men (24,6\%). Rate of dopamine agonist resistance was $15.9 \%$. We identified four significant predictors of dopamine agonist resistance: male gender, a large tumour volume, prolonged time to prolactin normalization and presence of a cystic, hemorrhagic and/or necrotic component. In addition, symptoms due to mass effect, high baseline prolactin level and a high contrast capture on MRI are factors that can be taken into consideration.

Conclusion: We identified predictive factors for pharmacological resistance and developed a scoring system for patient specific prediction of resistance to dopamine agonists. This scoring system may have impact on the timing and decision of surgery in prolactinoma patients after further prospective evaluation.
\end{abstract}

Keywords: Pituitary adenoma, Prolactinoma, Resistance, Dopamine agonist

\section{Background}

Pituitary adenomas are benign neuro-endocrine tumours and represent $10 \%$ of all intracranial tumours. The most common hormone-secreting pituitary tumours are prolactinomas, accounting for approximately 40\% [1-3]. Prolactin (PRL) secreting adenomas are particular in the responsiveness to a pharmacological therapy in contrast to other pituitary tumours [1].

* Correspondence: Sven.Glasker@vub.be

'Department of Neurosurgery, VUB University Hospital of Brussels, Laarbeeklaan 101, 1090 Brussels, Belgium

Full list of author information is available at the end of the article
Dopamine reduces the secretion of prolactin and 36 tumour volume by its suppressive effect on lactotrophic 37 cells in the pituitary and by lowering the angiogenesesis 38 in the surrounding tissue $[1,4]$. The first-line treatment 39 of prolactinomas with dopamine agonists (DA) is based 40 on this mechanism [5]. A minority (5-18\%) of patients 41 treated with dopamine agonists, nowadays mainly using 42 cabergoline $(\mathrm{CAB})$ instead of the older variant bromo- 43 criptine (BRC), do not achieve sufficient response. This 44 is most commonly owed to resistance or intolerance [2]. 45

At present, there is no universal definition of dopa- 46 mine agonist resistance. However, considering the pos- 47 sible detrimental effect of hyperprolactinemia as well as 48

(c) The Author(s). 2020 Open Access This article is licensed under a Creative Commons Attribution 4.0 International License, which permits use, sharing, adaptation, distribution and reproduction in any medium or format, as long as you give appropriate credit to the original author(s) and the source, provide a link to the Creative Commons licence, and indicate if changes were made. The images or other third party material in this article are included in the article's Creative Commons licence, unless indicated otherwise in a credit line to the material. If material is not included in the article's Creative Commons licence and your intended use is not permitted by statutory regulation or exceeds the permitted use, you will need to obtain permission directly from the copyright holder. To view a copy of this licence, visit http://creativecommons.org/licenses/by/4.0/ The Creative Commons Public Domain Dedication waiver (http://creativecommons.org/publicdomain/zero/1.0/) applies to the data made available in this article, unless otherwise stated in a credit line to the data. 
tumour volume, a reasonable definition is regarded as the failure to achieve prolactin normalization and/or a tumour size reduction in coronal surface of $\geq 50 \%$. The definition only applies after a minimum period of 3 months of receiving a daily dose of $15 \mathrm{mg}$ bromocriptine or a weekly dose of $3.0 \mathrm{mg}$ of cabergoline if tolerated [2]. Dopamine agonist resistance occurs in patients with micro- and macroprolactinoma, in 5 and $20 \%$ respectively $[2,3,6,7]$. Despite the fact that the side effects of DA are limited, the intolerance rate is estimated to be approximately $3-12 \%[2,8]$. Drug resistance and intolerance, together with patient's preference, diagnostic uncertainty and complications such as tumour apoplexy, visual impairment and cerebrospinal fluid (CSF) leakage due to shrinkage of the tumour are indications for transsphenoidal surgery [8]. The remission rate of surgery is approximately $73-90 \%$ in microprolactinoma cases and $33-56 \%$ in macroprolactinoma cases $[3,8]$. The side effects of surgery are rare and can be divided in two groups: the minor (3.5-6.5\%, e.g. septal perforation, epistaxis, wound infection, hematoma, CSF leak and diabetes insipidus) and major (1.5\%, e.g. vascular injury/ stroke, meningitis/abscess, visual loss and oculomotor injury) complications $[2,8]$.

When resistance (failure to achieve PRL normalization and/or a tumour size reduction of $\geq 50 \%$ ) is established to a particular patient, there are different therapeutic options [9]. One of the options is to switch to another DA since there is clear evidence that the switch to cabergoline can overcome resistance to bromocriptine, with a normalization of PRL and tumour mass reduction in 80 and $70 \%$ of the cases respectively $[3,6,8]$. Another approach is a step-up dose augmentation if tolerated (sideeffects are too prominent) and given a continued response. Although partial resistance may be suppressed by a gradual increase of the dosage of dopamine agonists, it seems that for cabergoline (regarded as the most efficient dopamine agonist) there is little benefit when increasing the dose above $3.0 \mathrm{mg}$ per week if continued for at least 3-6 months $[6,10]$. Another option is transsphenoidal surgery, which is widely considered as the next gesture in cases of DA resistance.

However, second line surgical resection of dopamine agonist resistant prolactinomas is frequently incomplete because of fibrotic changes of the tumour due to dopamine agonists $[11,12]$. Fibrosis and uneven shrinkage of the tumour can establish after 6 weeks of bromocriptine treatment $[11,12]$. A recent study showed that $77 \%$ of the prolactinomas with bromocriptine pretreatment were fibrotic. The probability of fibrosis (22\%) after 1 month cabergoline treatment was lower but still present [13]. Finding fibrosis at the time of surgery is considered as a negative predictive factor for complete biochemical remission after surgery ( $0 \%$ versus $37 \%)[1,8,13,14]$. As a consequence, the overall prolactin remission rate after second line surgery in patients with prolactinoma notresponding to dopamine agonists, is approximately $36 \%$ $[4,8]$. This is a considerably lower remission rate compared to about $87 \%$ in microprolactinoma and $56 \%$ in macroprolactinoma after first-line surgery, before the fibrotic changes can occur. In addition, complications such as diabetes insipidus are significantly more frequent as a post-operative complication in patients with bromocriptine pretreatment compared to non-pretreated prolactinomas [1]. Therefore, identifying the subgroup of patients with high risk of dopamine agonist resistance may be important since they could benefit from surgery early on in the course of the treatment given the better remission and complete resection outcome [7, 12]. In order to identify such subgroups of patients, we thought to investigate predictive factors of resistance to dopamine agonists in a consecutive series of prolactinoma patients treated at our hospital.

\section{Methods \\ Clinical data

To identify predictive factors of dopamine agonist resistance, we conducted a retrospective study based on a database of patients treated in a Belgian tertiary reference center from 2014 to 2016 after approval of the ethical commission of our hospital. From the moment of the start of the study, we went back in time to when a sufficient number of patients, determined in a power analysis, could be included.

Consent has been obtained from each patient after full explanation of the purpose and nature of all procedures. The inclusion criteria of the patients for this study were: age of 18 years or older, a confirmed prolactinoma and an available MRI before the start of therapy. The diagnosis of prolactinoma was based on the assessment of our endocrinologists. Here, clinical presentation, exclusion of other causes of hyperprolactinemia, MRI imaging and laboratory findings were taken into account. We considered the diagnosis of prolactinoma only in the presence of a corresponding MRI image and prolactin levels that were clearly elevated corresponding with levels at least 2 times higher than the upper limit of normal for microadenomas (except in one case) and at least 5 times higher than the upper limit of normal for macroadenomas and established on two separate occasions.

Patients with familial tumour syndromes such as multiple endocrine neoplasia type 1 (MEN1) were excluded.

Clinical data with possible predictive relevance were extracted from the patient's records: sex, age, age at diagnosis, presence of sexual dysfunction (amenorrhea or oligomenorrhea, infertility, decreased libido, erectile disorder) or galactorrhea, presence of mass effects and the duration of the symptoms before diagnosis. Mass 112 113 114 115 116 117 118 119 120 127 128 129 130 
effects disembosom: headache, dizziness, visual defects (abnormal visual field or eye movement disorder) and cranial neuropathy.

The biochemical data we determined, were the levels of PRL, insulin like growth factor -I (IGF-I), thyroid stimulating hormone (TSH) and adrenocorticotropic hormone $(\mathrm{ACTH})$ and we quoted the presence of sex hormone deficiency defined as decreased gonadotropins or testosterone.

Furthermore we examined biochemical data as well as different MRI variables such as the volume of the tumour ( $\mathrm{h} \times \mathrm{l} \mathrm{x} \mathrm{w} \mathrm{x}(\pi / 6)$ ); the shape of the tumour (being a sphere or bifocal); the intensity factor which is calculated as the ratio between the intensity of the tumour and the intensity of the grey matter (displayed in pixel value, PV), always consequently at the level of the superior temporal gyrus. Contrast enhancement, which is the ratio of the density factor on $\mathrm{T} 1$ after contrast to the value on $\mathrm{T} 1$ without contrast, was likewise computed. We also investigated parameters for follow up regarding the evolution of the tumour volume and the prolactin level.

The dosage of cabergoline was monitored during treatment in order to evaluate the response.

The dopamine agonist dosing regimen was clinically adjusted and examined as follows. Effect of DA treatment was re-evaluated at least every 3 months. If the treatment goal was achieved in terms of prolactin level and tumour size, that same dose would have been continued. If treatment goal was not achieved, the dose would be augmented after evaluation by the endocrinologists at the consultation.

When surgery was involved, a histological examination of the surgical specimen was always performed. Information about the Ki 67 (proliferation marker) level and the presence of sclerosis was hereby obtained. Sclerosis (augmentation of fibrous tissue) is considered negative when there was no mention of fibrosis, connective tissue or sclerosis in the operation report; and when it is not defined by the anatomy pathologist in the histological examination report of the surgical specimen.

Patients assigned to the responsive group had both prolactin normalization and a tumour volume shrinkage of $\geq 50 \%$ in coronal surface under dopamine agonist treatment. Resistance was concluded if no hormonal or tumoural response could be achieved after the next 1-2 consultations with a weekly dose up to $3.0 \mathrm{mg}$ cabergoline (see definition).

However, in that case, if tolerated and with the patient consent, the dosage would further be increased. The response was monitored throughout the follow-up (at least 12 months) and changed if there was a response after that further dose escalation.

Thereafter; a comparative study between the 2 groups, responsive versus resistant prolactinoma patients was performed.

\section{Statistical analysis}

The statistical analysis was performed using IBM SPSS statistics subscription software (International Business Machines Corp., Armonk, New York, USA). The level of significance was set at $P<0.05$. First, an exploratory analysis was performed wherein we examined for all factors whether there was a significant difference between the group of patients resistant to the dopamine agonists and the group that responds well to this first-line treatment. Chi-squared test ( $\chi^{2}$ test) was performed to compare count data. Wilcoxon-Mann-Whitney test and t-test were performed to compare continuous data. The aim of this explorative statistical phase was to select the most 222 promising predictive factors to include in the second 223 statistical analysis in order not to overfit the proceeding 224 analysis which would lower the predictive power. In the 225 second confirming statistical phase, a Fisher's linear dis- 226 criminant analysis was used to quantify the contribution 227 of all studied parameters in the prediction of possible re- 228 sistance to the dopamine agonist cabergoline. The fac- 229 tors which are included in this analysis were selected on 230 the basis of a (borderline) significant difference between 231 the 2 groups (in the first statistical phase) and/or a cor- 232 relation with resistance detected in previous literature. 233 The ultimate goal was to develop a scoring system for 234 practical use in a clinical setting to assess resistance.

\section{Results}

A total of 69 patients of whom 52 women (75.4\%) and 238 17 men (24.6\%), were included in the study. There was a 239 fairly balanced ratio between the overall prevalence of 240 micro- and macroprolactinoma in our study population, 241 54.4 and $45.6 \%$ respectively (Table 1 ). However, there was a higher occurrence of macroprolactinomas in men compared to women $(88.2 \%$ in men versus $30.8 \%$ in women). The median baseline prolactin level, before start of the therapy, was $116.98 \mu \mathrm{g} / \mathrm{l}$ (interquartile range, $\mathrm{IQR}=294.46 \mu \mathrm{g} / \mathrm{l})$, with a lowest value of $26.03 \mu \mathrm{g} / \mathrm{l}$ and a highest of $4488.73 \mu \mathrm{g} / \mathrm{l}$.

Of the 67 included patients, 61 patients (91\%) were 249 treated with cabergoline and 4 patients (6\%) with 250 bromocriptine. In 2 patients (3\%) there was a switch 251 from one dopamine agonist to another during the course 252 of our study. The median dose of cabergoline in the total 253 study group was $0.5 \mathrm{mg} /$ week with an interquartile range 254 of $0.75 \mathrm{mg} /$ week. Transsphenoidal resection of the aden- 255 oma was performed in 9 patients, representing 13\% of 256 the study population. In two patients, surgery was per- 257 formed as first-line treatment due to patient preference 258 or compression of the optic chiasm. Resistance to dopa- 259 mine agonist was the underlying cause for second line 260 surgery in 6 out of 7 patients. One patient was intolerant 261 to the dopamine agonists. Histological analysis of the 262 
t1.2

t1.3

t1. 4

t1.5

t1.6

t1.7

$\mathrm{t} 1.8$

t1.9

t1. 10

t1.11

t1.12

t1.13 MRI factors

t1. 14

t1. 15

t1.16

t1.17

t1.18

t1.19

Table 1 Descriptive parameters of the total study population

\begin{tabular}{|c|c|c|c|c|}
\hline & & Study population & Responsive group & Resistant group \\
\hline \multirow[t]{3}{*}{ Demographic factors } & Patients & 69 & 58 & 11 \\
\hline & Women & 52 & 46 & 6 \\
\hline & Men & 17 & 12 & 5 \\
\hline \multirow[t]{5}{*}{ Endocrinological factors } & $\begin{array}{l}\text { Baseline PRL } \\
\text { [median (interquartile range)] }\end{array}$ & $116.98 \mu \mathrm{g} / \mathrm{l}(294,46)$ & $105.66 \mu \mathrm{g} / \mathrm{l}(284,17)$ & $259.77 \mu \mathrm{g} / \mathrm{l}(842,24$ \\
\hline & $\begin{array}{l}\text { PRL after } 3 \text { months: Reduction } \\
\text { [mean (standard deviation)] }\end{array}$ & $83.3 \%(20.56)$ & $85.9 \%[11,15]$ & $67.5 \%(31,75)$ \\
\hline & PRL after 3 months: Normalization & $62.0 \%$ & $70.5 \%$ & $0.0 \%$ \\
\hline & $\begin{array}{l}\text { PRL after } 4 \text { months: Reduction } \\
\text { [mean (standard deviation)] }\end{array}$ & $82.7 \%(22,85)$ & $87.4 \%(18,95)$ & $63.8 \%(30,32)$ \\
\hline & PRL after 4 months: Normalization & $79.0 \%$ & $87.5 \%$ & $0.0 \%$ \\
\hline \multirow[t]{5}{*}{ MRI factors } & $\begin{array}{l}\text { Tumour volume } \\
\text { [median (interquartile range)] }\end{array}$ & $0.18 \mathrm{~cm}^{3}(1,32)$ & $0.13 \mathrm{~cm}^{3}(0,88)$ & $3.34 \mathrm{~cm}^{3}[5,7]$ \\
\hline & Microadenoma & $54.4 \%$ & $59.6 \%$ & $27.3 \%$ \\
\hline & Macroadenoma & $45.6 \%$ & $40.4 \%$ & $72.7 \%$ \\
\hline & $\begin{array}{l}\text { Contrast capitation } \\
\text { [mean (standard deviation)] }\end{array}$ & $1.93(0,81)$ & $1.88(0,70)$ & $2.40(1,43)$ \\
\hline & Presence of cystic/hemorraghic/necrotic component & $26.7 \%$ & $20.7 \%$ & $71.4 \%$ \\
\hline
\end{tabular}

t2.1 Table 2 Descriptive parameters of the resistant patients

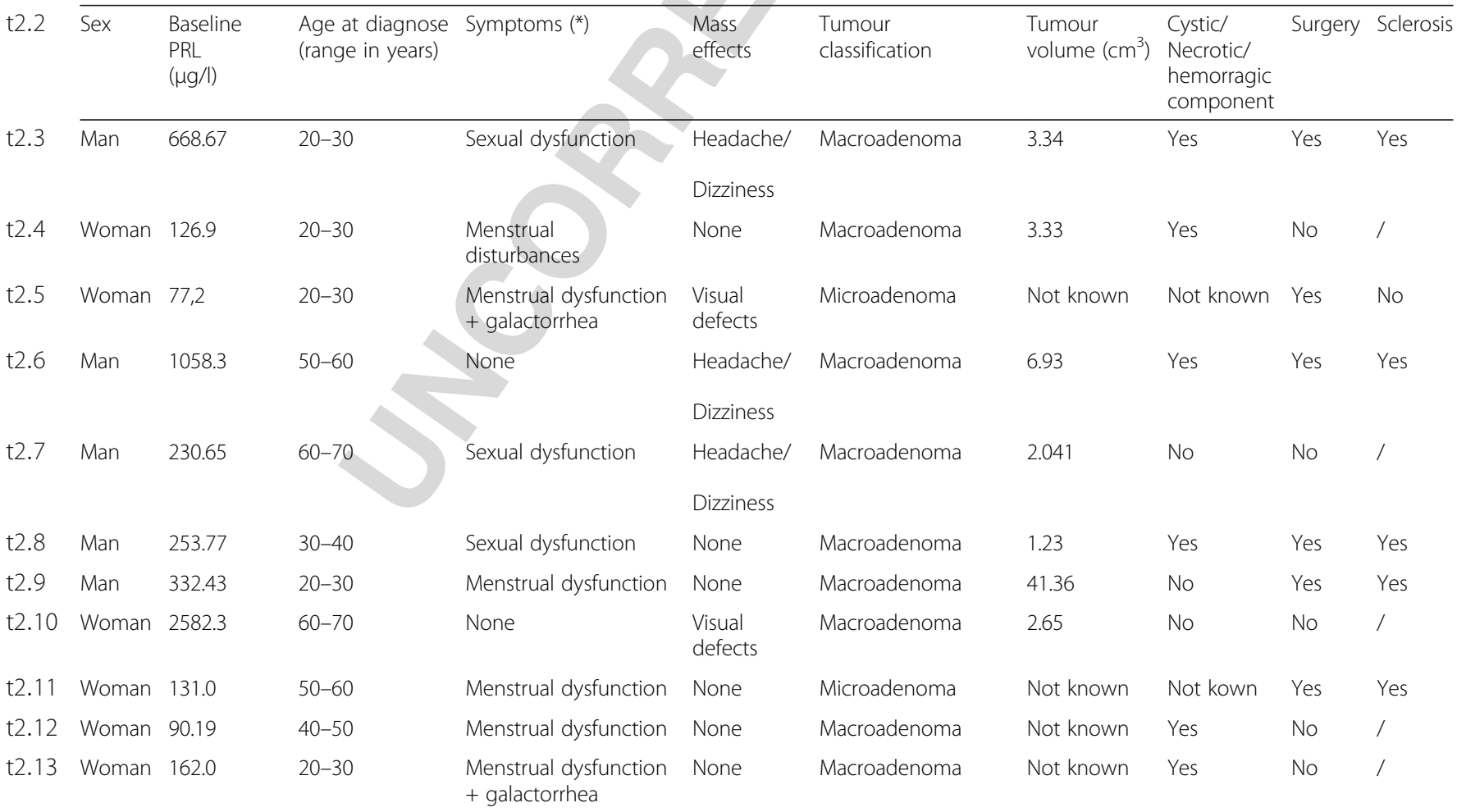

t2.14 (*) Sexual dysfunction: Decreased libido + Erectile disorder; Menstrual disturbance: Amenorrhea + Infertility 
surgically resected tissue confirmed the diagnosis in all cases. In the 2 patients who underwent early surgery, there was neither sclerosis nor an elevated Ki67 level. The Ki 67 level of patients who underwent surgery after DA pretreatment was increased in 3 out of 4 .

Resistance to dopamine agonists is seen in 11 of the 69 patients, representing $15,9 \%$ of our total study population.

\section{Dopamine agonist responsive versus resistant patients}

The total study population was divided into 2 groups. The first group consists of 58 patients that had sufficient response to dopamine agonist (= responsive group). The remaining 11 patients pertain the resistant group (Table 2). Causes of resistance in this second group were: absence of prolactin normalization $(5 / 11),<50 \%$ tumour volume shrinkage $(1 / 11)$ or the failure of both hormonal and tumour response (5/11). The demography of the 2 groups was mainly different in terms of gender with more men found in the resistant group compared to the responsive group ( $45.5 \%$ vs. $20.7 \%$ respectively; $p=0.08)$.

Although, the presence of symptoms was evenly distributed among both groups, the isolated occurrence of visual defects was only seen in case of resistance.

Time to prolactin normalization appeared to have a significant association with resistance $(p=0.008)$. Analyses of the MRI images of the pituitary gland showed an association between dopamine agonist resistance and tumour classification (micro- or macroadenoma). Here, $72.7 \%$ of the resistant tumours were macroadenoma, compared to $40.4 \%$ in the non-resistant group. The median tumour volume in the resistant group was $3.21 \mathrm{~cm}^{3}$ higher $(p=0.02)$ than in the group of patients respond- 294 ing well to the dopamine agonists $\left(0.13 \mathrm{~cm}^{3}\right)$ (Fig. 1$) . \quad 295$

Furthermore, significantly more patients in the dopa- 296 mine agonist resistant group revealed the presence of a 297 cystic, necrotic or hemorrhagic component on MRI (be- 298 fore the start of the pharmacological treatment) com- 299 pared to the responsive group $(71.43 \%$ versus $20.75 \% 300$ respectively; $p=0.004$ ).

Regarding the tumour density factors, only contrast enhancement appeared to be a possible predictive factor for resistance to dopamine agonists $(28 \%$ higher in the resistant group).

\section{Prediction model}

Based on a linear discriminant analysis, we were able to 307 statistically quantify the contribution of all factors in the 308 prediction of resistance to the dopamine agonist caber- 309 goline (Wilks lambda significance). It is noteworthy that 310 baseline prolactin level did not appear to make a signifi- 311 cant contribution to this prediction. Tumour volume 312 and the classification of the tumour in micro- or macro- 313 adenoma are both significant predictors. Since these var- 314 iables are clearly interrelated, we decided to only include 315 the most powerful factor which turned out to be the 316 tumour volume (Standardized Canonical Discriminant 317 Function Coefficient of 0.381 versus 0.070). 318 After eliminating the weakest predictors, we came up 319 with a strong model where 4 factors can determine the 320 response to dopamine agonists with nearly 85\% cer- 321 tainty. The 4 most powerful predictors are: sex, tumour 322 volume, the moment of prolactin normalization and the 323 presence of a cystic, hemorrhagic or necrotic component 324 (before the start of the dopamine agonist treatment). 325

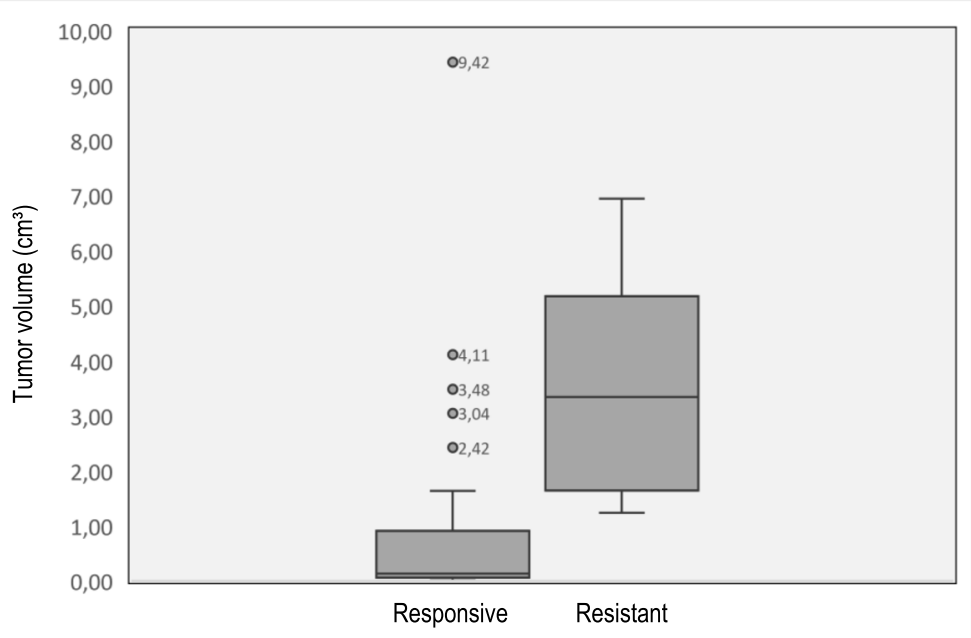

Fig. 1 Comparison of tumour volume in the responsive and resistant patient subgroup (significantly higher in resistant prolactinomas, $p=0.015$, Mood's median test, 95\% Cl) 


\begin{tabular}{|c|c|c|c|}
\hline \multirow[t]{2}{*}{ Sex } & Man & 7 points & \\
\hline & Woman & 0 points & \\
\hline Tumor Volume & {$[h \times I \times w \times(\pi / 6)]$} & $\begin{array}{l}\text { Absolute number }\left(\mathrm{cm}^{3}\right) \\
=\text { number of points }\end{array}$ & $\begin{array}{l}\text { Non-resistant: } \\
<18 \text { points }\end{array}$ \\
\hline \multirow[t]{2}{*}{$\begin{array}{l}\text { Cystic/hemorrhagic/necrotic } \\
\text { component }\end{array}$} & Yes & 12 points & $\begin{array}{l}\text { Grey zone: } \\
18-24 \text { points }\end{array}$ \\
\hline & No & 0 points & \multirow{3}{*}{$\begin{array}{l}\text { Resistant: } \\
>24 \text { points }\end{array}$} \\
\hline \multirow[t]{4}{*}{ PRL normalization } & $1^{\text {st }}$ month & 4 points & \\
\hline & $2^{\text {th }}$ month & 8 points & \\
\hline & $3^{\text {th }}$ month & 12 points & \\
\hline & $4^{\text {th }}$ month or later & 16 points & \\
\hline
\end{tabular}

Fig. 2 Scoring table (prediction model) based on 4 identified factors (sex, tumour volume, time to prolactin normalization and the presence of a

These are scored using a specialized scoring system (Fig. 2). Weaker predictors such as the presence of visual defects, a high baseline prolactin level and a high contrast enhancement on MRI, can also be taken into account for the clinical decision. In our study population itself, $89.5 \%$ could be correctly classified on the basis of the scoring system if the cut-off of 20 points was considered.

\section{Discussion}

In the present retrospective study, we thought to investigate possible predictive factors of pharmacological resistance of prolactinomas to dopamine agonists.

As expected, we found a higher general frequency of microprolactinomas compared to macroprolactinomas. There was a higher incidence of macroprolactinomas in men $(88.2 \%)$ compared to women $(30.8 \%)$. This trend is by analogy with previous literature [16-18].

The correlation we found between the (isolated) presence of visual defects and resistance was confirmed in literature, although they did not investigate the association with other combined mass effects such as headaches [15]. We have only found a significant difference between both groups when comparing patients who merely had visual defects at time of diagnosis.

In accordance with the guidelines of the Pituitary Society for the diagnosis and management of prolactinomas [5], 97\% of our patients received dopamine agonists as first-line treatment for their prolactinoma. In these patients, we found $15.9 \%$ to be resistant to dopamine agonists treatment, which is in accordance with previous data on this issue in literature, reporting resistance rates between 10 to $18 \%[3,6,8,19]$.

Subsequently, we have shown that male gender, a large tumour volume, prolonged time to prolactin normalization and presence of a cystic, hemorrhagic and/or necrotic com- 360 ponent (before the start of the pharmacological treatment) 361 had an important contribution in the prediction of resist- 362 ance to dopamine agonists in prolactinoma patients. The 363 results of our study extend previous studies.

The proposition that resistance to dopamine agonists is seen more frequently in men has previously been acknowledged in literature and is commonly adopted in clinical practice $[16,17]$. Some authors believe that this is due to a higher incidence of macroadenomas in men. This higher incidence of macroadenomas in men could 370 on the one hand be explained by the less obvious clinical 371 symptoms compared to those in women [3]. On the 372 other hand, Delgrange et al. postulated a different patho- 373 genesesis in men compared to women. This is supported 374 by the evidence that higher counts of cells with positive 375 Ki67 proliferation markers were found in male patients 376 $(2.6+/-1.1 \%$ of positive nuclei) compared to female pa- 377 tients (versus $0.4+/-0.2 \%$ of positive nuclei) when pro- 378 lactinomas of similar size were taken into consideration 379 $[20,21]$. This may explain an independent relationship 380 between sex and resistance.

The strongest endocrinological predictor of resistance to dopamine agonists in our study appeared to be the time to prolactin normalization. Since there is a clearly defined dosage escalation protocol by Pfizer $^{\circledast}$ in the tablet prescribing information, which is applied in most centers, time to prolactin normalization can be considered as a parameter. The association between the lack of prolactin normalization during medical therapy with a more aggressive evolution of prolactinoma and a higher proliferative potential, has already been reported $[17,21]$.

In contrast to what could have been expected from literature, we found no significant difference in baseline prolactin level between the two groups, nor did we find , 69 . . . . . , . 

448 brosis $[13,24]$.
We have provided a predictive model for dopamine re- 449 sistance based on the identified predictive factors. If 450 dopamine resistance is suspected, surgery could be of- 451 fered as an alternative first-line treatment instead of 452 medical treatment [25]. Indeed, remission rates of surgi- 453 cal resection as high as $91 \%$ have been reported espe- 454 cially in the case of microprolactinomas, and if 455 performed by an experienced surgeon, the risk of com- 456 plications remains relatively small $(1,5 \%-6,5 \%)[2,8]$. 457

\section{Conclusion}

We retrospectively analyzed a rather limited although 459 highly representative database of a Belgian tertiary refer- 460 ence centre for patients with pituitary tumours. 461

We developed a prediction model based on the 4 most 462 powerful predictors of resistance to dopamine agonists 463 being male gender, a great tumour volume, prolonged 464 time to prolactin normalization and the existence of a 465 cystic, hemorrhagic or necrotic component (before the 466 start of the pharmacological treatment). $\quad 467$

The scoring system is meant to be a tool to objectively 468 evaluate the patient's response to the dopamine agonists 469 early in the course of treatment. In this way, patients 470 who are at high risk of resistance can be identified early 471 and operated before the fibrosis which is induced by 472 long term dopamine agonist therapy, occurs. To com- 473 pensate for the inaccuracy of this model, a grey zone 474 was built in. Weaker predictors such as the presence of 475 visual defects, a high baseline prolactin level and a high 476 contrast enhancement on MRI, are factors that can be 477 taken into account for further interpretation for patients 478 scoring within that grey zone.

This scoring system may have impact on the timing 480 and decision of surgery in prolactinoma patients after 481 further prospective evaluation.

\section{Abbreviations}

ACTH: Adrenocorticotropic hormone; BRC: Bromocriptine; CAB: Cabergoline; 484 CSF: Cerebrospinal fluid; DA: Dopamine agonists; $h \times 1 \times$ w: Height $\times$ length $x \quad 485$ width; IGF-I: Insulin like growth factor -I; IQR: Interquartile range; 486 MRI: Magnetic resonance imaging; PRL: Prolactin; PV: Pixel value; TSH: Thyroid 487 stimulating hormone; $x^{2}$ test: Chi-squared test

SG and JD had the idea for the study. SG and EV developed the investigation protocol. TS designed the protocol for evaluation of MRT data. 493 EV, W and DU evaluated the clinical data. EV performed the statistical 494 calculation under supervision of KB. EV wrote the manuscript under 495 supervision of SG and DU. All authors read and approved the final 496 manuscript. 


\section{Availability of data and materials}

503 The datasets used and/or analyzed during the current study are not publicly

504 available due to privacy matters but are available from the corresponding

505 author on reasonable request.

506 Ethics approval and consent to participate

507 This study was approved by the Ethics Committee of the University Hospital

508 of Brussels (reference no.: 2017/128). Consent to participate is not applicable.

509 Consent for publication

510 Not applicable.

\section{Competing interests}

512 We declare that there is no conflict of interest that could be perceived as

513 prejudicing the impartiality of the research reported.

\section{Author details}

$515{ }^{1}$ Department of Neurosurgery, VUB University Hospital of Brussels,

516 Laarbeeklaan 101, 1090 Brussels, Belgium. ${ }^{2}$ Department of Radiology, VUB

517 University Hospital of Brussels, Laarbeeklaan 101, 1090, Brussels, Belgium.

$518{ }^{3}$ Department of Endocrinology, VUB University Hospital of Brussels,

519 Laarbeeklaan 101, 1090, Brussels, Belgium. ${ }^{4}$ Department of Statistics, VUB

520 University Hospital of Brussels, Laarbeeklaan 101, 1090, Brussels, Belgium.

521 Received: 29 April 2019 Accepted: 4 May 2020

522

\section{References}

524 1. Cao Y, Wang F, Liu Z, Jiao B. Effects of preoperative bromocriptine treatment on prolactin-secreting pituitary adenoma surgery. Exp Ther Med. 2016;11(5):1977-82.

2. Smith TR, Hulou MM, Huang KT, Gokoglu A, Cote DJ, Woodmansee WW, et al. Current indications for the surgical treatment of prolactinomas. J Clin Neurosci. 2015;22(11):1785-91.

3. Colao A. Pituitary tumours: the prolactinoma. Best Pract Res Clin Endocrinol Metab. 2009;23(5):575-96.

Vasilev V, Daly AF, Vroonen L, Zacharieva S, Beckers A. Resistant prolactinomas. J Endocrinol Investig. 2011;34(4):312-6.

5. Casanueva FF, Molitch ME, Schlechte JA, Abs R, Bonert V, Bronstein MD, et al. Guidelines of the pituitary society for the diagnosis and management of prolactinomas. Clin Endocrinol. 2006;65(2):265-73.

6. Molitch ME. Dopamine resistance of prolactinomas. Pituitary. 2003;6(1):19-27.

7. Colao A, di Sarno A, Pivonello R, di Somma C, Lombardi G. Dopamine receptor agonists for treating prolactinomas. Expert Opin Investig Drugs. 2002;11(6):787-800.

8. Hamilton DK, Vance ML, Boulos PT, Laws ER. Surgical outcomes in hyporesponsive prolactinomas: analysis of patients with resistance or intolerance to dopamine agonists. Pituitary. 2005:8(1):53-60.

Melmed S, Casanueva FF, Hoffman AR, Kleinberg DL, Montori VM, Schlechte $\mathrm{JA}$, et al. Diagnosis and treatment of hyperprolactinemia: an Endocrine Society clinical practice guideline. J Clin Endocrinol Metab. 2011;96(2):273-88.

10. Delgrange E, Daems T, Verhelst J, Abs R, Maiter D. Characterization of resistance to the prolactin-lowering effects of cabergoline in macroprolactinomas: a study in 122 patients. Eur J Endocrinol. 2009;160(5): $747-52$.

1. Lee Y, Ku CR, Kim EH, Hong JW, Lee EJ, Kim SH. Early prediction of longterm response to cabergoline in patients with macroprolactinomas. Endocrinol Metab (Seoul). 2014;29(3):280-92.

12. Bevan JS, Adams CB, Burke CW, Morton KE, Molyneux AJ, Moore RA, et al. Factors in the outcome of transsphenoidal surgery for prolactinoma and non-functioning pituitary tumour, including pre-operative bromocriptine therapy. Clin Endocrinol. 1987;26(5):541-56.

13. Menucci M, Quinones-Hinojosa A, Burger P, Salvatori R. Effect of dopaminergic drug treatment on surgical findings in prolactinomas. Pituitary. 2011;14(1):68-74.

14. Landolt AM, Keller PJ, Froesch ER, Mueller J. Bromocriptine: does it jeopardise the result of later surgery for prolactinomas? Lancet. 1982; 2(8299):657-8.

5. Vale FL, Deukmedjian AR, Hann S, Shah V, Morrison AD. Medically treated prolactin-secreting pituitary adenomas: when should we operate? Br J Neurosurg. 2013;27(1):56-62.
16. Oh MC, Aghi MK. Dopamine agonist-resistant prolactinomas. J Neurosurg. 567 2011:114(5):1369-79.

17. Delgrange E, Duprez T, Maiter D. Influence of parasellar extension of macroprolactinomas defined by magnetic resonance imaging on their responsiveness to dopamine agonist therapy. Clin Endocrinol. 2006;64(4): $456-62$.

18. Vroonen L, Jeffrain-Rea MLL, Petrossians P, Tamagno G, Chanson P, Vilar L et al. Prolactinomas resistant to standard doses of cabergoline: a multicenter study of 92 patients. Eur J Endocrinol. 2012;167(5):651-62. 575

19. Molitch ME. Management of medically refractory prolactinoma. J Neuro- 576 Oncol. 2014:117(3):421-8.

20. Delgrange E, Trouillas J, Maiter D, Donckier J, Tourniaire J. Sex-related 578 difference in the growth of prolactinomas: a clinical and proliferation 579 marker study. J Clin Endocrinol Metab. 1997;82(7):2102-7. 580

21. Delgrange E, Sassolas G, Perrin G, Jan M, Trouillas J. Clinical and histological 581 correlations in prolactinomas, with special reference to bromocriptine 582 resistance. Acta Neurochir. 2005;147(7):751-7 discussion 7-8. 583

22. Alkabbani AG, Mon SY, Hatipoglu B, Kennedy L, Faiman C, Weil RJ, et al. Is a 584 stable or decreasing prolactin level in a patient with prolactinoma a 585 surrogate marker for lack of tumor growth? Pituitary. 2014;17(2):97-102. 586

23. Gonzaga MFM, de Castro LF, Naves LA, Mendonca JL, Oton de Lima B, 587 Kessler I, et al. Prolactinomas Resistant to Treatment With Dopamine 588 Agonists: Long-Term Follow-Up of Six Cases. Front Endocrinol (Lausanne). 589 2018:9:625.

24. Ono M, Miki N, Kawamata T, Makino R, Amano K, Seki T, et al. Prospective 591 study of high-dose cabergoline treatment of prolactinomas in 150 patients. 592 J Clin Endocrinol Metab. 2008;93(12):4721-7.

25. Babey M, Sahli R, Vajtai I, Andres RH, Seiler RW. Pituitary surgery for small 594 prolactinomas as an alternative to treatment with dopamine agonists. 595 Pituitary. 2011;14(3):222-30.

\section{Publisher's Note}

Springer Nature remains neutral with regard to jurisdictional claims in published maps and institutional affiliations.
570 571

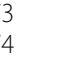
5 67 9

1

2

585

585
586
587

588

590
593 595

Ready to submit your research? Choose BMC and benefit from:

- fast, convenient online submission

- thorough peer review by experienced researchers in your field

- rapid publication on acceptance

- support for research data, including large and complex data types

- gold Open Access which fosters wider collaboration and increased citations

- maximum visibility for your research: over 100M website views per year

At BMC, research is always in progress.

Learn more biomedcentral.com/submissions 